\title{
Evaluation of Electrical Performance and Life Estimation of PPs for HVDC Power Cable
}

\author{
Seung-Won Lee ${ }^{1} \mathbb{D}$, Hae-Jong Kim ${ }^{1}$, Ik-Su Kwon ${ }^{1}$ and Jang-Seob Lim ${ }^{2, *}$ \\ 1 Superconductivity Research Center, Korea Electrotechnology Research Institute, Seongju-dong, \\ Changwon-si 51543, Korea; 815lsw@keri.re.kr (S.-W.L.); hjkim@keri.re.kr (H.-J.K.); iskwon@keri.re.kr (I.-S.K.) \\ 2 Division of Marine Mechatronics, Mokpo National Maritime University, Mokpo-si 58654, Korea \\ * Correspondence: Janylim@mmu.ac.kr; Tel.: +82-055-280-2535
}

Citation: Lee, S.-W.; Kim, H.-J.;

Kwon, I.-S.; Lim, J.-S. Evaluation of

Electrical Performance and Life Estimation of PPs for HVDC Power Cable. Energies 2021, 14, 5673 https://doi.org/10.3390/en14185673

Academic Editors: Mario Marchesoni, Ching-Ming Lai and Yitao Liu

Received: 6 August 2021

Accepted: 8 September 2021

Published: 9 September 2021

Publisher's Note: MDPI stays neutral with regard to jurisdictional claims in published maps and institutional affiliations.

Copyright: (c) 2021 by the authors. Licensee MDPI, Basel, Switzerland. This article is an open access article distributed under the terms and conditions of the Creative Commons Attribution (CC BY) license (https:// creativecommons.org/licenses/by/ $4.0 /)$.

\begin{abstract}
Demand and need for the application of high voltage direct current (HVDC) are increasing because of high capacity and long-distance transmission. Research on polypropylene (PP) that can increase the operation temperature compared to existing insulation is constantly being considered. This study aimed to evaluate the electrical performance and estimate the life of HVDC application of PP. In this study, a DC V-t characteristic tests were conducted on three types of PP sheets at a temperature of $110^{\circ} \mathrm{C}$. In addition, a life estimation formula based on the electrical stress was derived and the electrical performances were evaluated. The experimental results show that the life exponent of material mixed with block copolymer, homo polymer and high density polyethylene (HDPE) was 23 and the electrical performance was 17\% better than block copolymer, thereby demonstrating the reliability and electrical performance for application of HVDC.
\end{abstract}

Keywords: HVDC; polypropylene; life exponent; V-t characteristic test; long term reliability; life estimation

\section{Introduction}

Demand for high voltage direct current (HVDC) is increasing due to higher voltage of power cables and long-distance transmission. Classically, the insulations for HVDC uses mass oil, which has recently been converted to polymers due to environmental, production, and transmission capacity issues [1-3]. Among them, polypropylene (PP) has an operating temperature of $110^{\circ} \mathrm{C}$, has a higher transmission capacity than existing mass impregnated (MI), oil filled (OF) and cross linked polyethylene (XLPE), and can be recycled. Currently in terms of cable insulation, $\mathrm{PP}$ has a lot of interest $[4,5]$.

In general, the design life of HVDC MI, OF and XLPE power cables is 30 to 40 years. Since HVDC cables are operated underground or on the seabed for a long period of time, the evaluation of life and long-term reliability is considered as an important factor for the development of DC insulating materials [6,7].

This study aimed to evaluate the electrical performance and long-term reliability of PPs for HVDC application.

Several researchers are using the conductivity, space charge, dielectric strength, V-t characteristic test, partial discharge (PD) and dissipation factor to evaluate reliability of materials [8-15]. Among them, the V-t characteristic test is believed to be major factor contributing toward the evaluation of long term reliability using life exponent $[13,15,16]$. Other researchers used the life exponent that is a simple numerical value to assess the reliability of XLPE, epoxy, polypropylene laminated paper (PPLP) and low density polyethylene (LDPE) materials. The life exponent of materials ranged from 15 to 30 based on additive type and AC and DC application [13-19]. However, as the design life of power cables was not considered when evaluating the long-term reliability, it is impossible to determine the performance of materials during actual operation. Above all, the reliability evaluation and life estimation of PPs for HVDC application has not been considered yet. 
In general, the breakdown voltage of an insulating material depends on the temperature and the pressure applied to the test sample $[20,21]$. However, during the V-t characteristic test, the temperature of the test object could not be known in real time because the dummy sample was not installed, and there was no description of a method that could equalize the measuring force of the samples.

Unlike previous studies, we calculated the life exponent of PPs that can increase the transmission capacity and demonstrated the HVDC applicability by comparing life exponent of other materials. Furthermore, the electrical performance of PPs with a design life of 40 years for power cables was evaluated and priorities were established. In addition, the failure data was analyzed using the Weibull distribution, the value of $63.2 \%$ of the Weibull distribution function of the data of time to breakdown was applied to derive the lifetime estimation according to the electrical stress. Temperature sensors were installed in the dummy sample to improve the reliability of the V-t characteristic test of the PPs, the electrodes and micrometer were combined so that the uniform measuring force was applied to the sheets.

As for the test contents, a short-term ascent test and a V-t characteristic test were conducted at $110^{\circ} \mathrm{C}$ on three types of PP sheets in which block copolymer, homo polymer and high density polyethylene (HDPE) were mixed.

This paper contributes to long-term reliability and life evaluation during research and development of HVDC insulating materials, and the calculated life exponent should be used as a reference for calculating the deterioration coefficient with the type and prequalification (PQ) test of PP cables for application of HVDC [22].

The remainder of this paper is organized as follows. Section 2 presents the discussion of the theory for calculating the life exponent and life estimation formula and Weibull distribution. In addition, we propose a circuit for V-t test. In Section 3, we demonstrate how to conduct the $\mathrm{V}$-t characteristic test at $110{ }^{\circ} \mathrm{C}$ and Section 4 presents the evaluation of electrical performance.

\section{Theory}

\subsection{Inverse Power Law}

Insulating materials for power cables are exposed to various stresses. As the operating time of the cable increases, aging progresses and the insulation performance degrade. V-t test is an experimental method based on electrical stress of aging factors. As a result, the life exponent $\mathrm{n}$ and the formula of life estimation due to electrical stress can be calculated, and it is mainly used in the long-term reliability evaluation method. The equation of V-t is as follows $[23,24]$.

$$
\mathrm{V}^{\mathrm{n}} \times \mathrm{t}=\mathrm{k}
$$

The life equation using Equation (1) is as follows.

$$
\mathrm{L}(\mathrm{V})=\mathrm{kV}^{-\mathrm{n}}
$$

where $\mathrm{L}$ is the time-to-breakdown in hours, usually it is the Weibull probability of $63.2 \%, \mathrm{~V}$ is the applied voltage to materials, and $n, k$, are constants to be determined for the specific tested material or device. The inverse power law is considered valid, if the data being plotted on log-log graph fits a straight line [25].

In Equation (2), $\mathrm{n}$ is called the life exponent and is used to evaluate the long-term reliability of insulating materials and calculate the aging factor [22]. The output formula of the $\mathrm{n}$ is as follows. Figure 1 shows the V-t characteristic curve.

$$
\begin{gathered}
\mathrm{V}_{1}^{\mathrm{n}} \times \mathrm{t}_{1}=\mathrm{V}_{2}^{\mathrm{n}} \times \mathrm{t}_{2} \\
\mathrm{n}=\frac{\log \left(\frac{\mathrm{t}_{2}}{\mathrm{t}_{1}}\right)}{\log \left(\frac{\mathrm{V}_{1}}{\mathrm{~V}_{2}}\right)}
\end{gathered}
$$




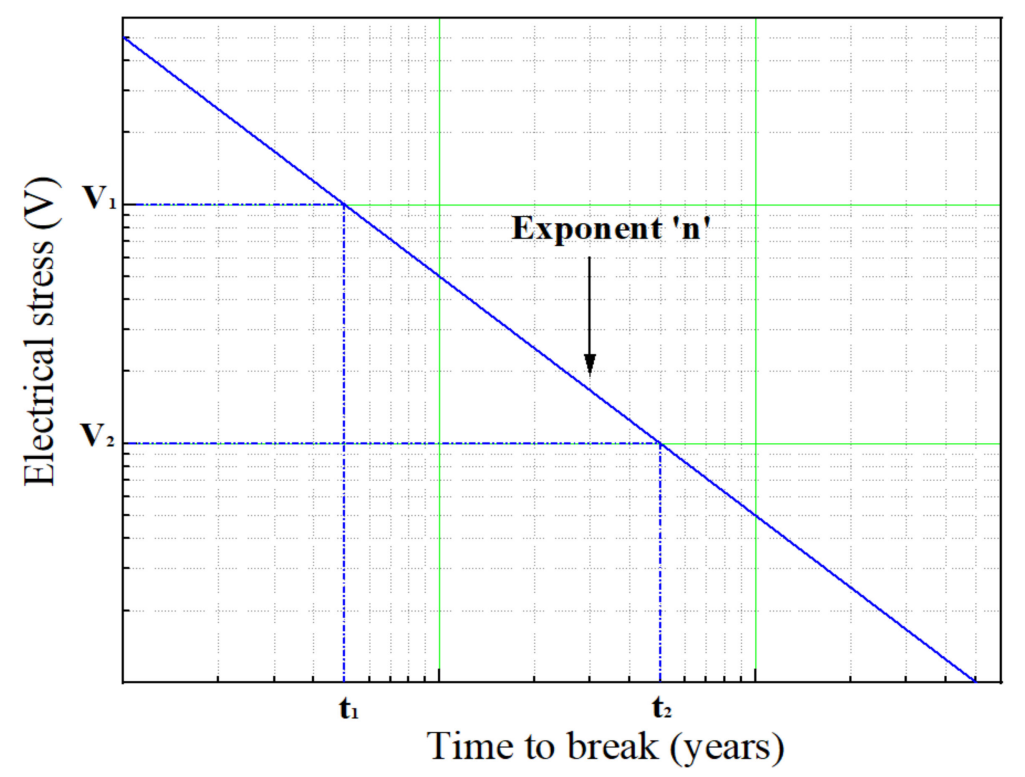

Figure 1. The V-t characteristic curve.

\subsection{Weibull Distribution}

Statistical methods such as normal distribution, exponential distribution, logarithmic distribution and Weibull distribution are used to analyze and evaluate the failure data of materials. Among them, the Weibull distribution function is widely used for the reliability analysis of products associated with failures because it is possible to determine the failure modes in the early, constant, and wear out failures by using the scale parameter and shape parameter [26,27]. The following is the formula for the two-parameter Weibull distribution function [28].

$$
\mathrm{F}(\mathrm{t})=1-\exp \left[-\left(\frac{\mathrm{t}}{\alpha}\right)^{\beta}\right]
$$

In the equation, $t$ represents the breakdown time, $F(t)$ is the probability of failure, alpha is a scale parameter greater than 0 , and means the $63.2 \%$ value of the failure probability. In the case of beta, it is a shape parameter, which means the type of data.

\section{Experimental}

\subsection{Test Sample}

In general, PPs are divided into two types, homo polymer and copolymer, depending on the use of co-monomer. Homo polymer refers to polypropylene obtained by polymerizing only propylene monomer without using co-monomer. Further, as a general copolymer, there is a block copolymer polymerized by adding ethylene to propylene. Homo polymer has the advantages of heat resistance, mechanical properties, chemical resistance, and recycling, but is vulnerable to impact resistance at low temperatures. In the case of block copolymer, the impact resistance was improved.

The materials were blended with different proportions of block copolymer, homo polymer and HDPE. Table 1 shows three types of the test samples. The block polymer was selected because it best suits the properties required for the cable, and when the homo polymer and block polymer are mixed in half, it was selected to confirm the recyclability of the homo polymer. Furthermore, the quantity of ethylene included in the block copolymer of this paper was about $15 \%$, and the reason why HDPE was mixed with the mixture of homo polymer and block copolymer was because of corrosion resistance, and the reason why homo polymer and block polymer had a larger ratio than HDPE was to emphasize the heat resistance of PP. In general, submarine and underground cables are corroded from various sources. HDPE has better corrosion resistance than LDPE, XLPE and other materials and has the advantage of melting. 
Table 1. The test samples for V-t characteristic test.

\begin{tabular}{c} 
Description of the Test Samples \\
Block copolymer $=100 \%$ \\
Block copolymer : Homo polymer $=50 \%: 50 \%$ \\
Block copolymer : Homo polymer : HDPE $=30 \%: 30 \%: 40 \%$ \\
\hline
\end{tabular}

Prior to sheet production, the hot press was heated to $200{ }^{\circ} \mathrm{C}$ for $5 \mathrm{~min}$. Then, compound supplied by the cable manufacture was added to the molding flask, and the mixture was pressurized at $10 \mathrm{MPa}$ for $5 \mathrm{~min}$, and rapidly cooled for $2 \mathrm{~min}$ using a cooling press of $10^{\circ} \mathrm{C}$. Figure 2 shows the equipment for manufacturing the PP sheets and the completed test sample.
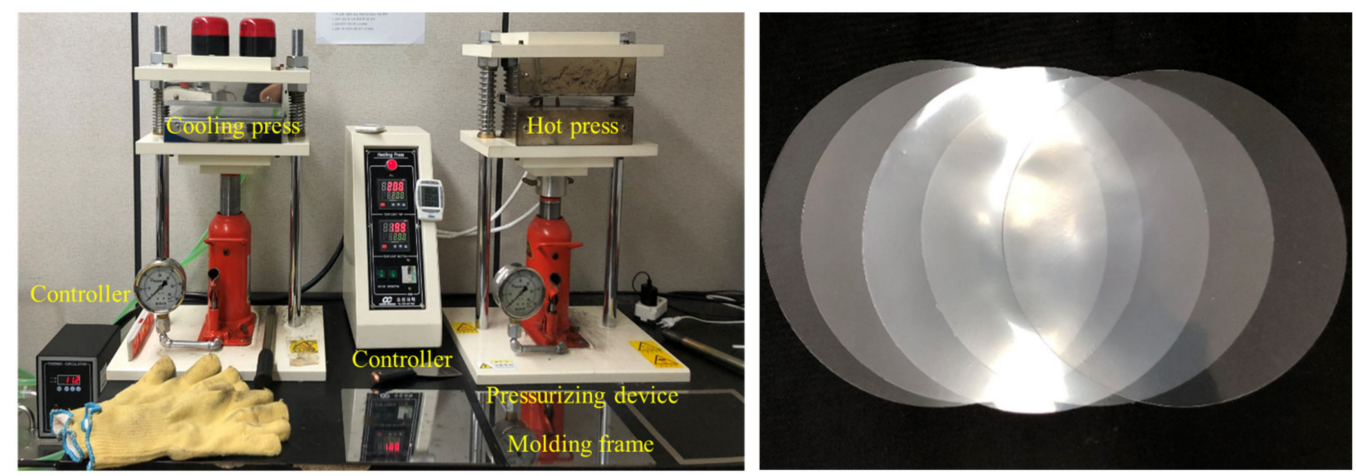

Figure 2. The equipment for manufacturing test samples.

The outer diameter of the PP sheet was $22 \mathrm{~cm}$, the thickness was $0.2 \mathrm{~mm}$, and the error range of the thickness was within $5 \%$.

With reference to the IEC 62431 standard, the number of specimens for the ramping test was set to 10 [29]. In addition, the V-t characteristic test was performed 20 times, and 5 specimens per test voltage were used.

\subsection{Experimental Setup}

HVDC generator, voltage dividers, oven, oil bath, data acquisition system (DAS) and PC for temperature measurement were used as equipment for the breakdown test of PP materials.

The HVDC voltage source has a maximum voltage and current of $120 \mathrm{kV}$ and $30 \mathrm{~mA}$, and is configured as a high-voltage transformer, a clamp circuit and peak detector that combines a capacitor and a diode, a protection resistor and a voltage divider. HVAC is generated from the transformer, DC voltage is superimposed via the clamp circuit, and HVDC is generated through the peak detector. The DC voltage from the power source is connected in series with the protection resistor and then applied in parallel to the voltage divider and the test sample. The applied HVAC transformer is $220 \mathrm{~V}$ input and $60 \mathrm{kV}$ output, and the diode is for rectifying the AC voltage. It is combined with a diode and a capacitor to the voltage doubler [30]. Capacitors and diodes were used that could withstand a HVDC voltage of $100 \mathrm{kV}$ or higher, and a limited resistor of $120 \mathrm{k} \Omega$ was also configured to protect the circuit from overvoltage and overcurrent when the test sample was breakdown. In addition, the voltage divider that connected $300 \mathrm{M} \Omega$ and $30 \mathrm{k} \Omega$ in series was used to measure the DC voltage applied to the test sample in real time. Figure 3 shows a circuit diagram for the HVDC generator. In general, in order to perform a DC breakdown test, the ripple factor of the HVDC generator is important, and its value must be $3 \%$ or less. Note that if the value is exceeded, DC voltage characteristics are not reflected in the test. 


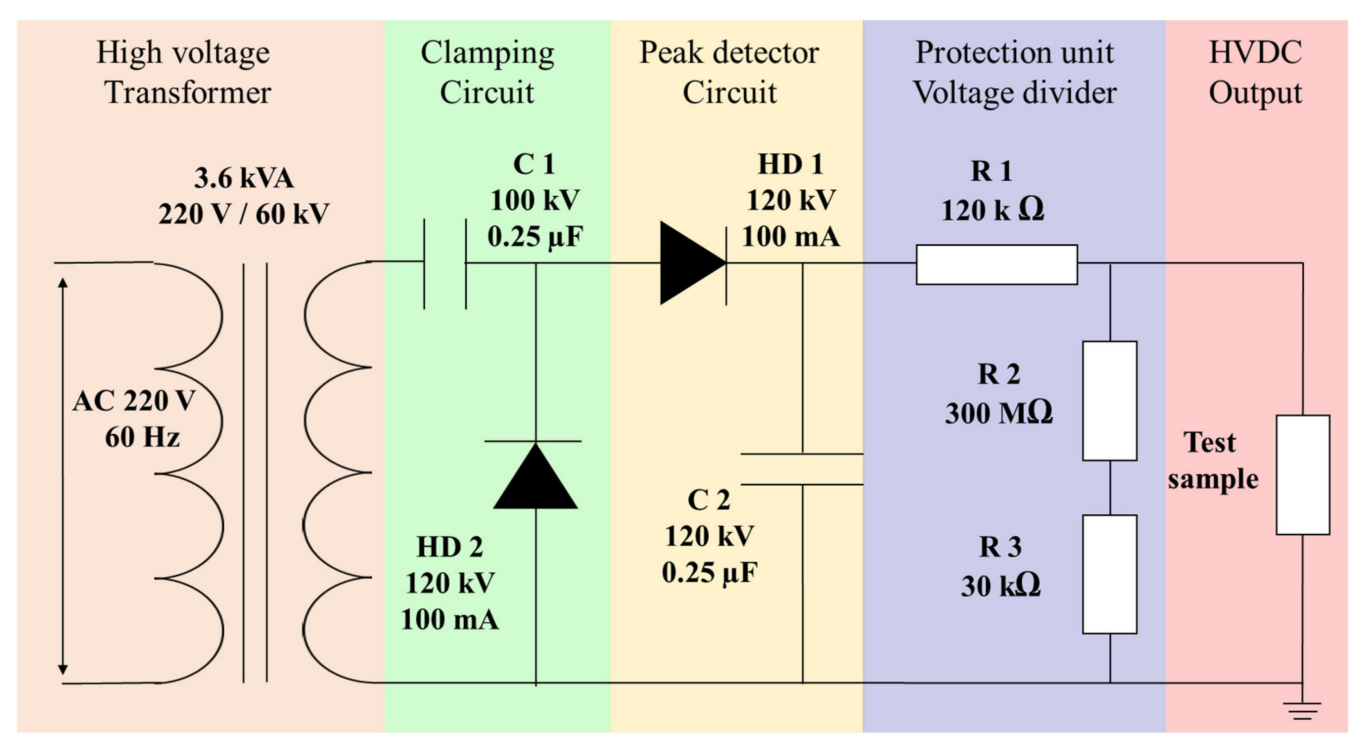

Figure 3. The circuit for breakdown voltage test.

Figure 4 shows the schematic representation of ramping and the V-t characteristic test. An oven was used to maintain a constant temperature of $110{ }^{\circ} \mathrm{C}$ for the test sample, and a temperature sensor was constructed to the dummy sample, and the temperature of the PPs was measured in real time. The transformer oil was put into an oil bath made of stainless steel to prevent flashover, and the oil bath was grounded. For the supporting structure of the breakdown test a polytetrafluoroethylene (PTFE) that was not deformed even at a temperature of $110{ }^{\circ} \mathrm{C}$ or higher was applied. A heat-resistant silicon-insulated cable was used to apply DC voltage in the air and oil inside the oven.

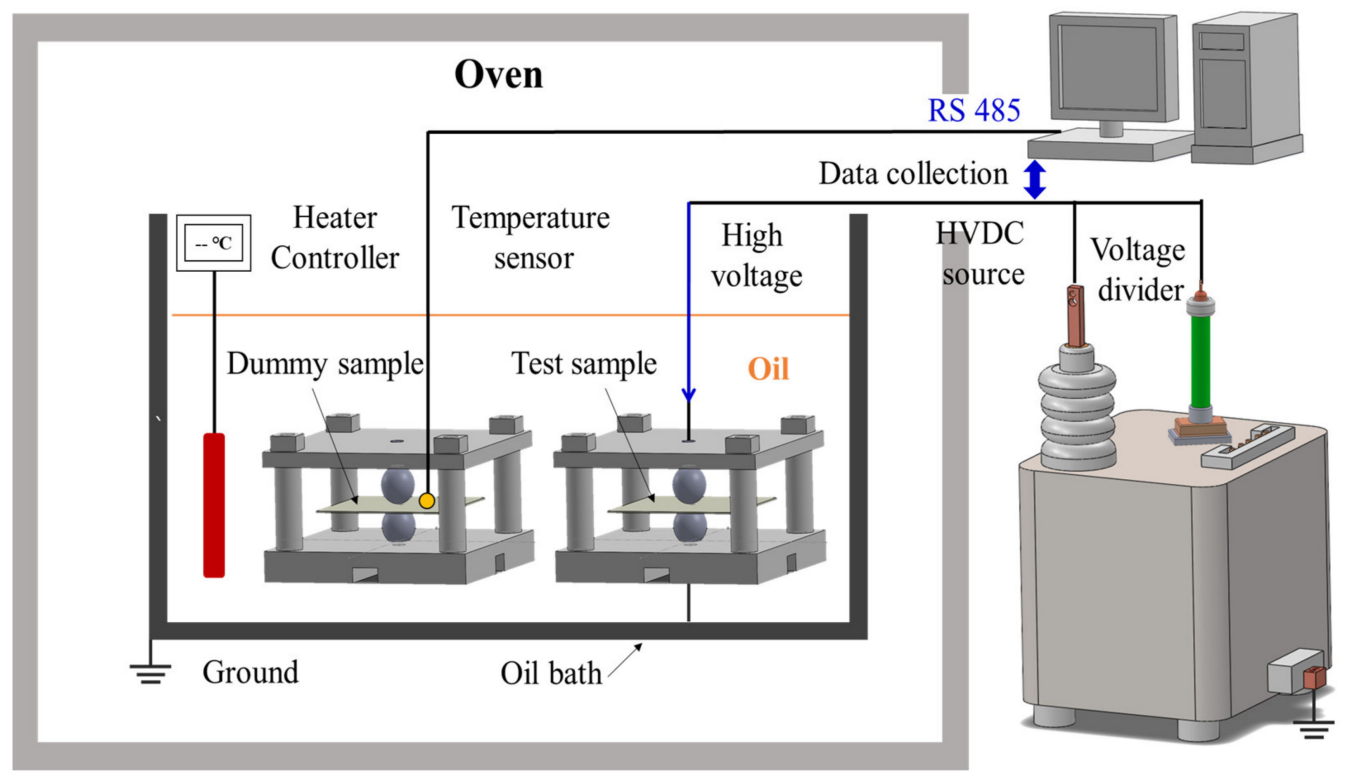

Figure 4. Schematic representation of the experimental setup for V-t characteristic test.

Commercialized micrometers and electrodes were combined for the constant measuring force applied to the test sample. The test electrodes were designed so that the constant force was applied to PP sheet during the V-t characteristic test. The electrode was made of a stainless steel with an outer diameter of $20 \mathrm{~mm}$ referring to the standard of IEC 62431 . The temperature and voltage applied to the test sample were saved in real time using RS 485 communication. Figure 5 is a picture of the test electrode and the V-t characteristic test inside the oven. 


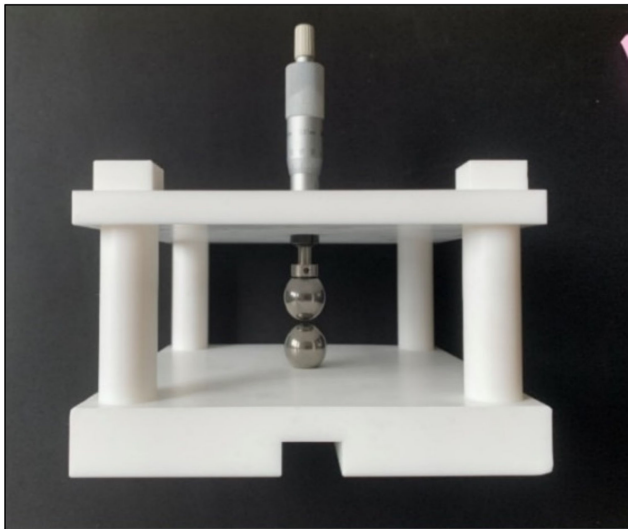

(a)

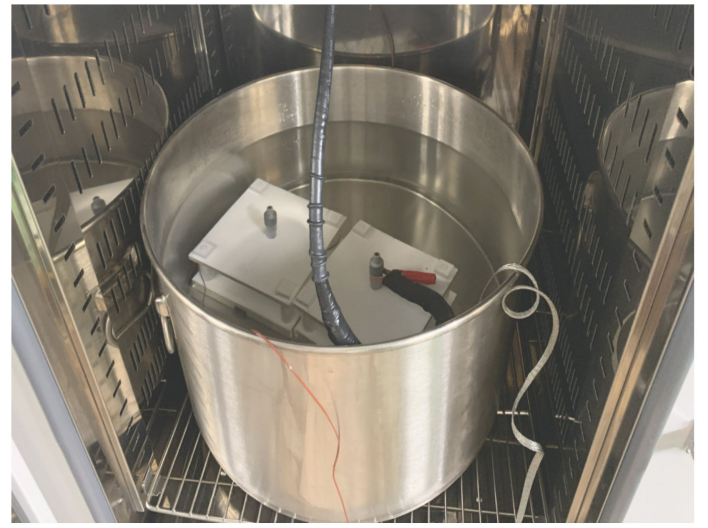

(b)

Figure 5. The pictures of V-t test: (a) electrode with micrometer and PTFE structure; (b) dummy sample inside oil for measuring temperature.

\subsection{Test Conditions}

The ramping test was performed under a step-up condition at $2 \mathrm{kV}$ per second in accordance with the IEC standard [29]. The DC V-t characteristic test was performed with voltage until it broke. The test was carried out while maintaining the constant operating temperature of $110^{\circ} \mathrm{C}$ for the PPs.

\section{Results}

\subsection{Ramping Test}

In order to determine the approximate test voltage of the V-t characteristic test, a ramping test was performed on three types of PPs, and the Weibull distribution $63.2 \%$ of breakdown data was $40 \mathrm{kV}$ or more. Figure 6 shows the breakdown data after the ramping test of the test samples as a Weibull distribution function. Table 2 specifies the scale and shape parameters of three types of PPs after ramping test.

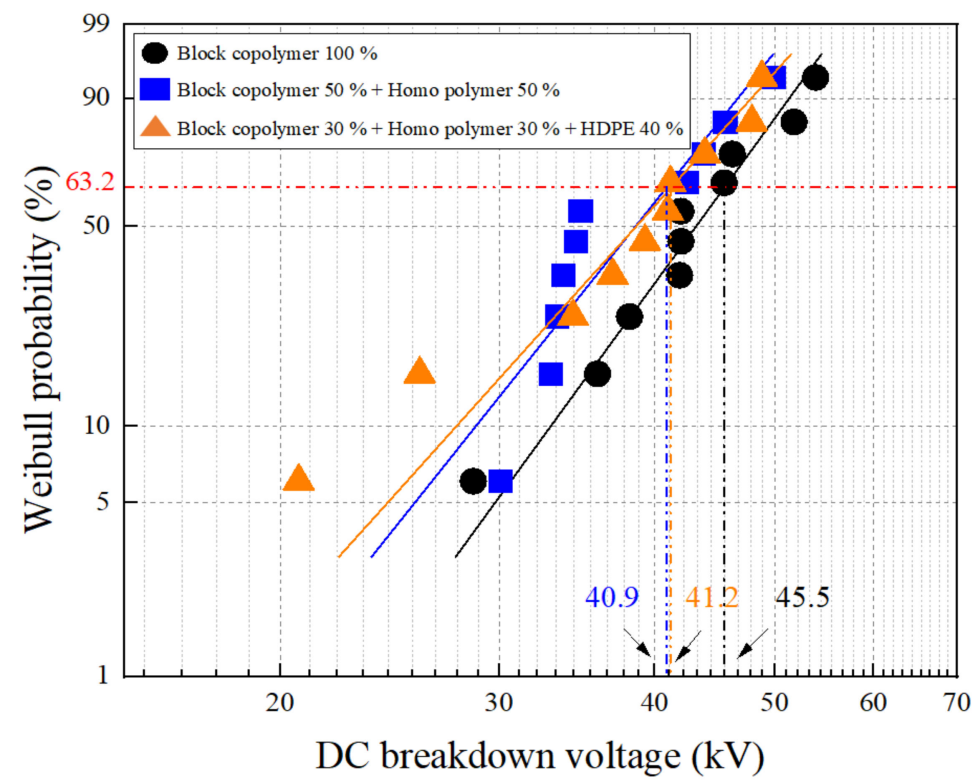

Figure 6. The Weibull distribution after ramping test of the test samples. 
Table 2. Specification of the scale and shape parameters of three types of test samples.

\begin{tabular}{cccc}
\hline & Block Copolymer $=\mathbf{1 0 0} \%$ & $\begin{array}{c}\text { Block Copolymer : Homo } \\
\text { Polymer }=\mathbf{5 0 \%}: \mathbf{5 0} \%\end{array}$ & $\begin{array}{c}\text { Block Copolymer : Homo Polymer : } \\
\text { HDPE = 30\% : 30\%: } \mathbf{4 0} \%\end{array}$ \\
\hline Scale parameter & 45.5 & 40.9 & 41.2 \\
Shape parameter & 6.9 & 6.3 & 5.6 \\
\hline
\end{tabular}

\subsection{DC $V$ - $t$ Test}

After the ramping test, a DC V-t characteristic test was performed based on a breakdown voltage of $63.2 \%$. For the test voltage, four voltage levels were applied between a maximum of 47 and $36 \mathrm{kV}$. The breakdown data according to time was plotted using the Weibull distribution function, and a V-t characteristic curve was made using the value of the breakdown time according to the applied voltage. The life exponent was calculated through the slope of the graph, and the life estimation equation of the PPs was derived through the relationship between voltage and time.

In Figures $7 a, 8 a$ and $9 a$ the analyses are shown of the breakdown data using the Weibull distribution function, and Figures $7 \mathrm{~b}, 8 \mathrm{~b}$ and $9 \mathrm{~b}$ display the figure for calculating the life exponent and life estimation equation. In Figures $7 b, 8 b$ and $9 b$, the red data is the Weibull $63.2 \%$ of the breakdown time according to the applied voltage, and the life estimation was derived from the four red data. In the figure, the fastest breakdown data in Figure 9 was $23 \mathrm{~s}$ when $47 \mathrm{kV}$ was applied, and the longest lasting data in Figure 8 was $87,138 \mathrm{~s}$ when the voltage $36 \mathrm{kV}$ was applied.

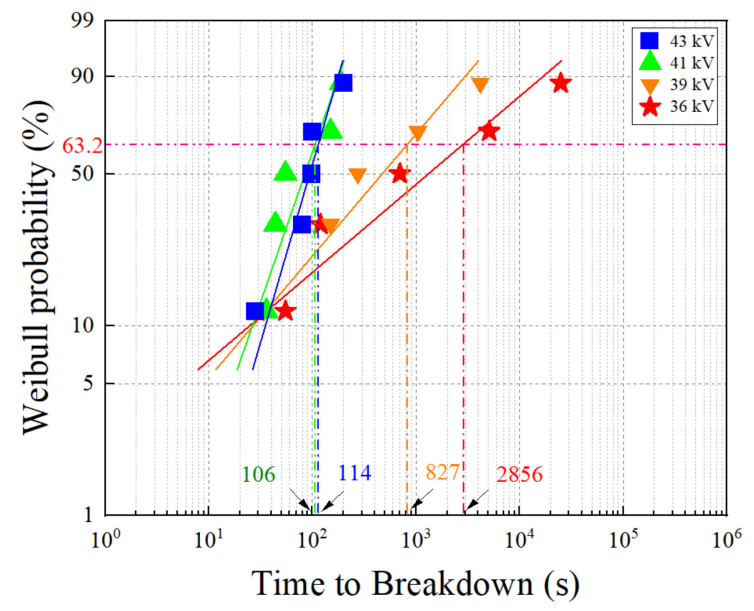

(a)

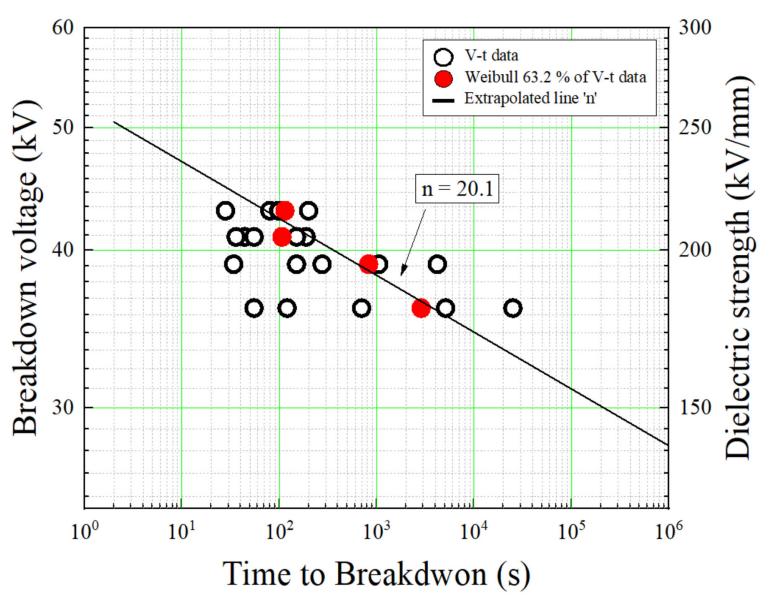

(b)

Figure 7. Breakdown data analysis on block copolymer: (a) Weibull distribution according to time to breakdown; (b) V-t graph to obtain life exponent and life estimation formula.

\subsection{Life Exponent and Estimation}

The V-t characteristic test was carried out on three types of PPs, and the V-t characteristic curve was drawn according to electrical stress. Using Equations (2) and (4), the life exponent $\mathrm{n}$ was calculated, and the life estimation formula was also derived.

In general, the life exponent is used in a way that makes it easy to evaluate the longterm reliability of insulating materials. It is judged that the larger the life exponent of the insulating materials, the better the life characteristics. Each life exponent is as follows: the block copolymer was 20.1, when the block copolymer and homo polymer PP were mixed, it was 21.1, and when the block copolymer PP, homo polymer and HDPE were mixed, it was 23.2. It was shown that as the mixture was added to the block copolymer, the long-term reliability properties improved. 


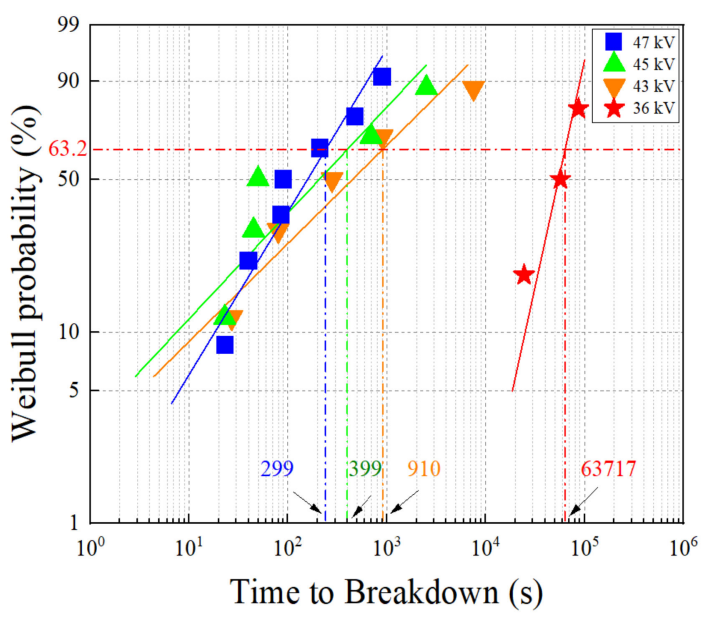

(a)

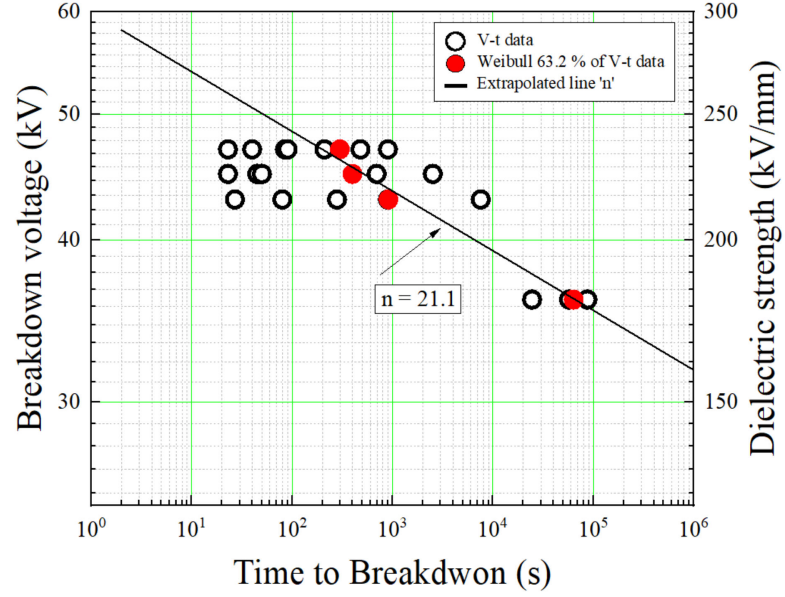

(b)

Figure 8. Breakdown data analysis on block copolymer and homo polymer: (a) Weibull distribution according to time to breakdown; (b) V-t graph to obtain life exponent and life estimation formula.

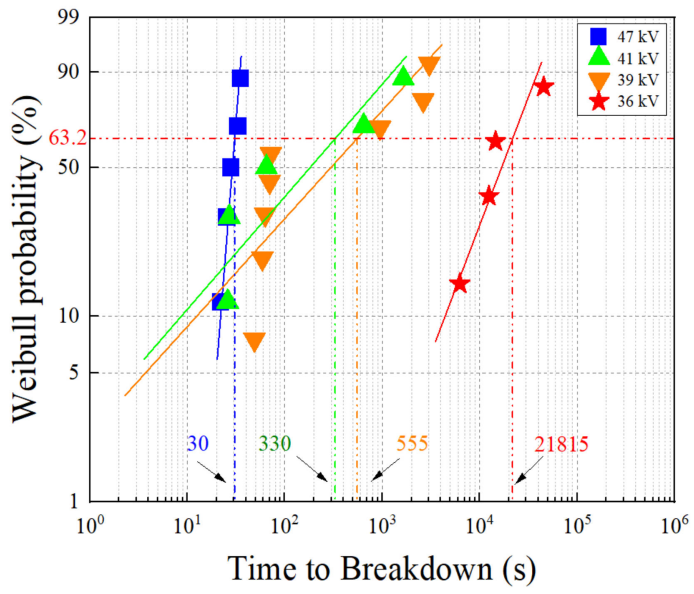

(a)

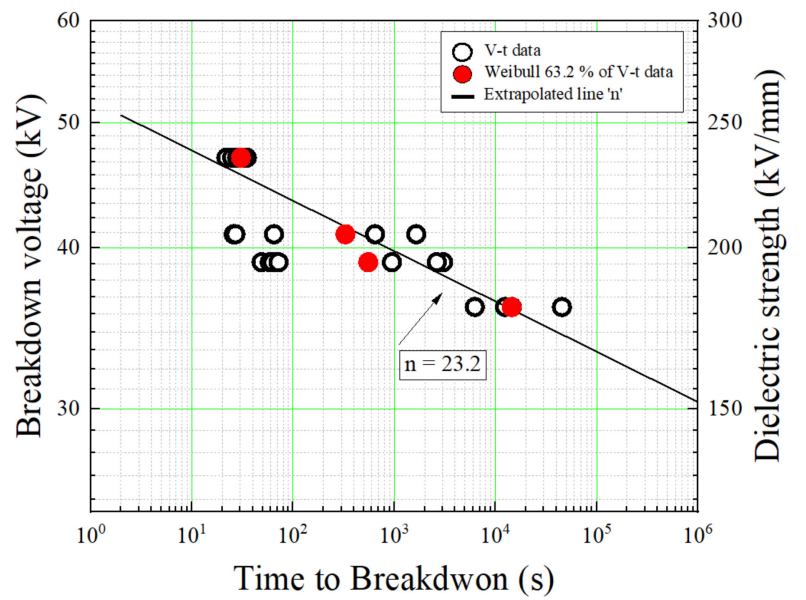

(b)

Figure 9. Breakdown data analysis on block copolymer, homo polymer and HDPE: (a) Weibull distribution according to time to breakdown; (b) V-t graph to obtain life exponent and life estimation formula.

Since the design life of a power cable is usually 40 years, an equation that can calculate the long-term operating life due to electrical stress was needed. Table 3 shows the life exponent and life estimation formula of other PPs with the mixing ratio of additives.

Table 3. The life exponent and life estimation formula according to PPs.

\begin{tabular}{ccc}
\hline Description of the Test Samples & $\begin{array}{c}\text { Life } \\
\text { Exponent }\end{array}$ & $\begin{array}{c}\text { Life Estimation } \\
\text { Formula }\end{array}$ \\
\hline $\begin{array}{c}\text { Block copolymer }=100 \% \\
\text { Block copolymer : Homo polymer } \\
=50 \%: 50 \%\end{array}$ & 20.1 & $\mathrm{~L}(\mathrm{~V})=6 \times 10^{34} \times \mathrm{V}^{-20.13}$ \\
$\begin{array}{c}\text { Block copolymer : Homo polymer : HDPE } \\
=30 \%: 30 \%: 40 \%\end{array}$ & 21.1 & $\mathrm{~L}(\mathrm{~V})=4 \times 10^{37} \times \mathrm{V}^{-21.09}$ \\
& 23.2 & $\mathrm{~L}(\mathrm{~V})=10^{40} \times \mathrm{V}^{-23.23}$ \\
\hline
\end{tabular}

\subsection{Evaluation of Electrical Performance}

The use of life exponent in assessing long-term reliability and performance is very relative. So, we required a way to express the electrical performance as a percentage. 
Figure 10 shows the electrical stress of 100 years of PP insulating material using the lifetime equation and when comparing the three materials, the larger breakdown voltage value according to life is more economical because it can reduce the insulation thickness applied to the cable. Electrical performance was evaluated by electrical stress tolerance based on a block copolymer with a design life of 40 years as a standard. The PP with HDPE was 17\%, and the electrical performance was excellent. Table 4 shows the performance evaluation of dielectric strength of PPs in 40 years.

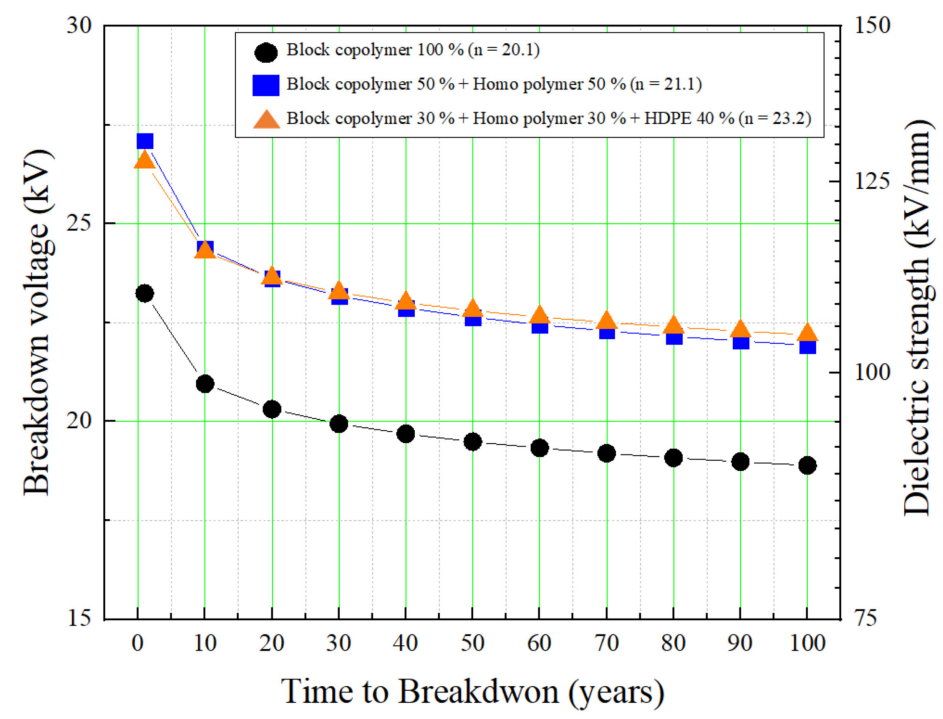

Figure 10. V-t curve considering the long term operation of power cables.

Table 4. Performance evaluation of dielectric strength of PPs in 40 years.

\begin{tabular}{ccc}
\hline Description of the Test Samples & Breakdown Voltage & Performance \\
\hline Block copolymer $=100 \%$ & $19.6 \mathrm{kV}$ & Benchmark \\
Block copolymer : Homo polymer & $22.8 \mathrm{kV}$ & $16 \%$ \\
$=50 \%: 50 \%$ & $23 \mathrm{kV}$ & $17 \%$ \\
$\begin{array}{c}\text { Block copolymer : Homo polymer : HDPE } \\
=30 \%: 30 \%: 40 \%\end{array}$ & & \\
\hline
\end{tabular}

\section{Discussion}

Many researchers have used the life exponent as a method for assessing long-term reliability, but some have not considered it in experiments and analyses.

Initially, the experimental part did not use a dummy sample during the $\mathrm{V}$-t test and did not present a method that could provide a uniform pressure on the test samples.

Second, the long-term reliability of the materials was evaluated only by the life exponent, which is a relative numerical value in the analysis. Based on the life equation, the evaluation of electrical performance at the design life of the cable should be performed.

In this study, dummy samples were used to measure temperature in real time, and a commercially available micrometer was used to present a method for a constant measuring force of samples. The $\mathrm{V}$-t characteristics test of the test samples was conducted at $110{ }^{\circ} \mathrm{C}$. As shown in Figures 7-9, the life exponent according to the breakdown voltage and time to breakdown is quantitatively calculated. The block copolymer had a value of 20.1, the case block copolymer and homo polymer were mixed, with a value of 21.1, and the block copolymer, homo polymer and HDPE were mixed, with a value of 23.2. We compared the electrical performance between the materials mixed block copolymer, homo polymer and HDPE to prove the long-term reliability and applicability of HVDC. In addition, we evaluated the electrical performance which is the cable design life of 40 years. The electrical performance of the insulation mixed block copolymer, homo polymer and HDPE is up 
to $17 \%$ higher than block copolymer. Additionally, it was found that the mixed material without HDPE was also about 16\% higher than the block copolymer, and the influence of HDPE seems to be inadequate. However, HDPE has a corrosion resistance to water, which will prevent the aging and failure due to moisture penetration of the submarine and underground cable and will ensure long-term reliability. Based on this study, evaluation of electrical performance with PPs when exposed to water is also essential, and further research on the long-term reliability of the block copolymer and HDPE mixed materials are not mentioned in this paper.

There are some points and limitations that need to be improved in this study. Since the content of this study is related to the life due to electrical stress, additional studies according to the thermal and mechanical properties are also required. In addition, the reliability of this model depends on the number of breakdown data. Because the Weibull distribution function is a statistic, the reliability of the analysis increases with more data. Conversely, this model is vulnerable and can fail if the amount of data is small. We test to meet the minimum number provided by the IEC and require additional testing to obtain more reliable results. Further study of the related attributes of conductivity and space charge for a DC application is also required. It is also necessary to evaluate the long-term reliability of cables to which PP insulating materials are applied. In this paper, we can contribute as a reference for HVDC application of PP and insulation, and contribute to the life and long-term reliability evaluation of insulating materials through the DC V-t.

In addition, as described in this paper, Figures 1 and 6, Figures 7-10 use a software program called Origin.

\section{Conclusions}

In this study, electrical performance was evaluated for HVDC application of PP. DC $\mathrm{V}$-t characteristics tests were performed on three types of $s$, the life exponent was calculated, and the life estimation equation of the PP insulating material due to electrical stress was derived.

The implications of this study can be summarized as follows. First, the life exponent of PPs is 20 or more, which is equivalent to or higher than that of conventional materials, demonstrating the applicability of HVDC. Second, the long-term reliability was evaluated by deriving the life estimation equation of PP insulating material due to electrical stress. Third, based on the third life estimation equation, the PP with HDPE had a 17\% better electrical performance than the block polymer based on the design life of the cable of 40 years.

Author Contributions: This paper is a result of the collaboration of all co-authors. S.-W.L. and I.-S.K. conceived and designed the study. H.-J.K. and S.-W.L. established the model and drafted the manuscript. J.-S.L. refined the language and provided statistical information. H.-J.K. helped with the corrections. S.-W.L. designed and performed the experiments. All authors have read and agreed to the published version of the manuscript.

Funding: This research was funded by the Ministry of Science and ICT (MSIT) (No. 21A01058).

Institutional Review Board Statement: Not applicable.

Informed Consent Statement: Not applicable.

Data Availability Statement: Not applicable.

Acknowledgments: This research was supported by Korea Electrotechnology Research Institute (KERI) Primary research program through the National Research Council of Science \&Technology (NST) funded by the Ministry of Science and ICT (MSIT) (No. 21A01058).

Conflicts of Interest: The authors declare no conflict of interest. 


\section{References}

1. Mazzanti, G.; Marzinotto, M. Extruded Cables for High-Voltage Direct-Current Transmission; Wlley-IEEE Press: Hoboken, NJ, USA, 2013; pp. 99-106.

2. Kazuki, T.; Sukuki, H.; Hara, M.; Watanabe, K. Research and development of /spl plusmn/250 kV DC XLPE cables. IEEE Trans. Power Deliv. 1998, 13, 7-16. [CrossRef]

3. Wang, H.; Cao, J.; He, Z.; Yang, J.; Han, Z.; Chen, G. Research on Overvoltage for XLPE Cable in a Modular Multilevel Converter HVDC Transmission System. IEEE Trans. Power Deliv. 2015, 31, 683-692. [CrossRef]

4. Huang, X.; Fan, Y.; Zhang, J.; Jiang, P. Polypropylene based thermoplastic polymers for potential recyclable HVDC cable insulation applications. IEEE Trans. Dielectr. Electr. Insul. 2017, 24, 1446-1456. [CrossRef]

5. Yoshino, K.; Ueda, A.; Demura, T.; Miyashita, Y.; Kurahashi, K.; Matsuda, Y. Property of Syndiotactic Polypropylene and Its Application to Insulation of Electric Power Cable -Property, Manufacturing and Characteristics. In Proceedings of the 7th International Conference on Properties and Applications of Dielectric Materials (ICPADM), Nagoya, Japan, 1-5 June 2003.

6. Rong, X.; Shaoxin, M.; Yuli, W. Long Term Reliability Tests of 500 kV XLPE Cable System. In Proceedings of the 2014 International Conference on Power System Technology, Chengdu, China, 20-22 October 2014. [CrossRef]

7. Nakiri, T.; Maekawa, Y.; Takashima, H.; Imajo, T.; Hirota, H.; Ishii, K.; Nakao, Y.; Shimada, M. Long-term reliability testing of 500 kV DC PPLP-insulated oil-filled cable and accessories. IEEE Trans. Power Deliv. 1999, 14, 319-326. [CrossRef]

8. Morette, N.; Ditchi, T.; Oussar, Y. Partial Discharges Measurements and Analysis as an Evaluation Tool for the Reliability of Polymeric-Insulated Cables used under HVDC Conditions. In Proceedings of the 2018 IEEE 2nd International Conference on Dielectrics (ICD), Budapest, Hungary, 1-5 July 2018. [CrossRef]

9. Wang, S.; Yu, S.; Xiang, J.; Li, J.; Li, S. DC breakdown strength of crosslinked polyethylene based nanocomposites at different temperatures. IEEE Trans. Dielectr. Electr. Insul. 2020, 27, 482-488. [CrossRef]

10. Zhang, C.C.; Li, Y.F.; Hu, M.Y.; Ma, F.L.; Zhao, H.; Han, B.Z. Conductivity Properties of XLPE Insulation Used for HVDC Cable after Accelerated Thermal Ageing. In Proceedings of the 2018 12th International Conference on the Properties and Applications of Dielectric Materials (ICPADM), Xi'an, China, 20-24 May 2018.

11. Dakka, M.A.; Bulinski, A.; Bamji, S. Correlation Between Space Charge Development and Breakdown in Polymeric Insulation under dc Field. In Proceedings of the 2004 IEEE International Conference on Solid Dielectrics, Toulouse, France, 5-9 July 2004.

12. Li, W.; Zhang, X.; Zhao, A.; Wu, L.; Ren, Z.; Deng, J.; Zhang, G. Studies of the Polarization/Depolarization Current Characteristics of XLPE Cable. In Proceedings of the 2016 IEEE PES Asia-Pacific Power and Energy Engineering Conference (APPEEC), Xi'an, China, 25-28 October 2016.

13. Shirasaka, Y.; Murase, H.; Okabe, S.; Okubo, H. Cross-sectional comparison of insulation degradation mechanisms and lifetime evaluation of power transmission equipment. IEEE Trans. Dielectr. Electr. Insul. 2009, 16, 560-573. [CrossRef]

14. Yoon, J.; Kwon, J.; Ryu, J.; Bae, C.; Choi, J.; Kim, Y. A Study of Relationship between V-t and Tan $\delta$ Characteristic on Epoxy Resin. In Proceedings of the 2019 IEEE Electrical Insulation Conference (EIC), Calgary, AB, Canada, 16-19 June 2019.

15. Lalam, F.B.; Djemmal, F. DC Electrical Ageing of XLPE under Hydrostatic Pressure. Adv. Mater. Sci. Eng. 2017, $2017,3936163$. [CrossRef]

16. Murata, Y.; Sakamaki, M.; Abe, K.; Inoue, Y.; Mashio, S.; Kashiyama, S.; Matsunaga, O.; Igi, T.; Watanabe, M.; Asai, S.; et al. Development of High Voltage DC-XLPE Cable System. SEI Tech. Rev. 2013, 101, 55-62.

17. Tiwana, A.P.S.; Reddy, C.C. Life Estimation of LDPE Film under Stepped-Stress Voltage Application. In Proceedings of the 2016 IEEE Conference on Electrical Insulation and Dielectric Phenomena (CEIDP), Toronto, ON, Canada, 16-19 October 2016.

18. Fujimori, A.; Tanaka, T.; Takashima, H.; Imajo, T.; Hata, R.; Tanabe, T.; Yoshida, S.; Kakihana, T. Development of 500 kV DC PPLP-insulated oil-filled submarine cable. IEEE Trans. Power Deliv. 1996, 11, 43-50. [CrossRef]

19. Wang, Y.; Lv, Z.; Wang, X.; Wu, K.; Zhang, C.; Li, W.; Dissado, L. Estimating the inverse power law aging exponent for the DC aging of XLPE and its nanocomposites at different temperatures. IEEE Trans. Dielectr. Electr. Insul. 2016, 23, 3504-3513. [CrossRef]

20. Xia, L.; Qinxue, Y.; Minghao, L.; Kai, Z.; Lisheng, Z. Temperature Dependence of AC / DC Breakdown Strength of HVDC XLPE Cable Slices. In Proceedings of the 2016 International Conference on Condition Monitoring and Diagnosis (CMD), Xi'an, China, 25-28 September 2016.

21. Hu, H.; Jia, Z.; Wang, X.; Shi, Z.; Zhang, C. Simulation of Mechanical Pressure of XLPE-SiR Interface in Cable Joints Based on Operating Temperature and Interference Parameters. In Proceedings of the 2020 IEEE International Conference on High Voltage Engineering and Application (ICHVE), Beijing, China, 6-10 September 2020.

22. Brochure CIGRE 496. Recommendations for Testing DC Extruded Cable Systems for Power Transmission at a Rated Voltage up to $500 \mathrm{kV}$; CIGRE Working Group B1.32; CIGRE: Paris, France, 2012.

23. Feilat, E.A.; Grzybowski, S.; Knight, P.J. Electrical Aging Models For Fine Gauge Magnet Wire Enamel of Flyback Transformer. In Proceedings of the IEEE SoutheastCon 2000, 'Preparing for The New Millennium' (Cat. No. 00CH37105), Nashville, TN, USA, 9 April 2000.

24. Matsumoto, S.; Sato, T.; Honda, H.; Yokoyama, S. Approximate Formula for Surface V-t Characteristics of 6.6-kV Distribution Insulator. In Proceedings of the 2012 International Conference on Lightning Protection (ICLP), Vienna, Austria, 2-7 September 2012. 
25. Ying, L.; Hui, B.; Yu, S.; Xiaolong, C. The Measurement of Voltage Endurance Coefficient by Electrical Treeing Test for XLPE Cable Insulation. In Proceedings of the 2013 IEEE International Conference on Solid Dielectrics (ICSD), Bologna, Italy, 30 June-4 July 2013.

26. Su, P.; Yin, Y.; Zheng, X.; Xuan, Y.; Wu, J. Investigation of the Thickness Effect on DC Breakdown Strength for HVDC Flexible Cable Insulation Associated with Space Charge. In Proceedings of the 2019 IEEE Electrical Insulation Conference (EIC), Calgary, AB, Canada, 16-19 June 2019.

27. Yuan, W.; Wang, T.; Ni, H.; Gao, M.; Ding, Y.; Li, Y.; Zhao, Y.; Zhang, Q. Weibull Statistical Analysis of Size Effects on the Impulse Breakdown Strength in Transformer Oil. In Proceedings of the 2017 IEEE 19th International Conference on Dielectric Liquids (ICDL), Manchester, UK, 25-29 June 2017.

28. Zhang, L.; Zhou, Y.; Cui, X.; Sha, Y.; Le, T.H.; Ye, Q.; Tian, J. Effect of nanoparticle surface modification on breakdown and space charge behavior of XLPE/SiO 2 nanocomposites. IEEE Trans. Dielectr. Electr. Insul. 2014, 21, 1554-1564. [CrossRef]

29. IEC 62431-1. Electric Strength of Insulating Materials-Test Methods-Part 1: Tests at Power Frequencies. 2013. Available online: https:/ / webstore.iec.ch/publication/1101 (accessed on 6 September 2021).

30. Kwon, J.-M.; Kwon, B.-K. High Step-Up Active-Clamp Converter with Input-Current Doubler and Out-put-Voltage Doubler for Fuel Cell Power Systems. IEEE Trans. Power Electron. 2009, 24, 108-115. [CrossRef] 